\title{
Zein-alpha lipoic acid-loaded nanoparticles to enhance the oral bioavailability of dapoxetine: optimization and clinical pharmacokinetic evaluation
}

This article was published in the following Dove Press journal:

International Journal of Nanomedicine

\begin{abstract}
Khalid M El-Say (D) ${ }^{1,2}$
Osama AA Ahmed (D) 1,3

Amir I Mohamed (D) ${ }^{4}$

Martin K Safo iD ${ }^{5}$

Abdelsattar M Omar 6,7

'Nanotechnology Laboratory,

Department of Pharmaceutics, Faculty of Pharmacy, King Abdulaziz University, Jeddah 21589, Saudi Arabia; ${ }^{2}$ Department of Pharmaceutics and Industrial Pharmacy, Faculty of Pharmacy, Al-Azhar University, Cairo II65I, Egypt; ${ }^{3}$ Department of Pharmaceutics and Industrial Pharmacy, Faculty of Pharmacy, Minia University, Minia 615/9, Egypt; ${ }^{4}$ Department of Pharmaceutics and Industrial Pharmacy, Military Medical Academy, Cairo, Egypt; ${ }^{5}$ Department of Medicinal Chemistry, and the Institute for Structural Biology, Drug Discovery and Development, School of Pharmacy, Virginia Commonwealth University, Richmond, VA 23298, USA; ${ }^{6}$ Department of Pharmaceutical Chemistry, Faculty of Pharmacy, King Abdulaziz University, Jeddah 21589, Saudi Arabia; ${ }^{7}$ Department of Pharmaceutical Chemistry, Faculty of Pharmacy, Al-Azhar University, Cairo I I884, Egypt
\end{abstract}

Correspondence: Khalid M El-Say Pharmaceutics and Industrial Pharmacy, Department of Pharmaceutics, Faculty of Pharmacy, King Abdulaziz University, P.O. Box: 80260 , Jeddah, Saudi Arabia

Tel +966 I26 40000020073

Fax +966 I2 6951696

Email kelsayl@kau.edu.sa
Background: Premature ejaculation (PE) is the most common type of male sexual disorder with important psychological consequences. Dapoxetine (DPX), a recently approved drug for the treatment of PE, suffers from low bioavailability with large variability that ranges from $15-76 \%$ (mean $42 \%$ ) after oral administration. The objective of this study is to optimize the parameters for the preparation of DPX-Zein-alpha lipoic acid (ALA) nanoparticles (NPs) to improve the bioavailability of DPX and consequently decrease therapeutic dose and adverse effect, leading to patient satisfaction and compliance.

Methods: We investigated the effect of ALA concentration, PVA concentration and stirring rate on nanoparticle size $\left(\mathrm{Y}_{1}\right)$, zeta potential $\left(\mathrm{Y}_{2}\right)$, initial DPX release $\left(\mathrm{Y}_{3}\right)$ and cumulative DPX release $\left(\mathrm{Y}_{4}\right)$. In addition, in vivo pharmacokinetic study was performed for the optimized DPX formulation on human healthy volunteers compared with marketed DPX tablet.

Results: The optimized DPX-loaded NPs showed $\mathrm{Y}_{1}, \mathrm{Y}_{2}, \mathrm{Y}_{3}$, and $\mathrm{Y}_{4}$ of $159.24 \mathrm{~nm}, 19.14 \mathrm{mV}$, $25.31 \%$ and $95.9 \%$, respectively. A single oral dose of $30 \mathrm{mg}$ of optimized DPX-loaded NPs to human volunteers resulted in 2-fold improvement of AUC (1376.145 \pm 339.592 vs 709.178 \pm 146.307 in DPX), 4-fold increase in $t_{\max }(2.5 \pm 0.314$ vs $0.583 \pm 0.144)$, prolongation of MRT (7.637 \pm 1.373 compared to $6.031 \pm 1.826 \mathrm{~h})$, but with reduction in $\mathrm{t}_{1 / 2}(5.283 \pm 1.077 \mathrm{vs} 8.452 \pm 2.813)$. Conclusion: The clinical findings suggest $194 \%$ enhancement of relative bioavailability of the optimized DPX-loaded NPs, potentially leading to a decrease in therapeutic dose and associated side effects in the treatment of PE.

Keywords: dapoxetine, premature ejaculation, mathematical experimental design, nanoparticles, clinical pharmacokinetics, bioavailability

\section{Introduction}

The Global Study of Sexual Attitudes and Behaviors (GSSAB) has reported the Premature ejaculation (PE) to be approximately $30 \%$ across all age groups. ${ }^{1-3} \mathrm{PE}$ is associated with serotonin neurotransmission imbalances, which is usually not related to other chronic disorders. ${ }^{4}$

Dapoxetine (DPX), with an antidepressant property, is the first serotonin transporter inhibitor successfully used for the treatment of PE. ${ }^{5-7}$ DPX increases the action of serotonin at the postsynaptic cleft. The fast-acting effect and rapid elimination of DPX make it a good candidate for the treatment of PE, but not as an antidepressant. The efficacy and safety of DPX in the treatment of PE were confirmed in 2011 and granted marketing 
authorization for $30 \mathrm{mg}$ and $60 \mathrm{mg}$ film-coated tablets in the European Union. ${ }^{8}$ Nonetheless, DPX suffers from low bioavailability with large variability $15-76 \%$ (mean $42 \%$ ) after oral administration. DPX is extensively metabolized through several pathways, for example Liver and kidney to give about 40 metabolites that are essentially inactive. Accordingly, formulation of DPX as Zein nanoparticles prolongs its circulation in the body and protects DPX from metabolism, hence improve DPX bioavailability and efficacy. ${ }^{9}$ The peak plasma concentration of DPX after oral administration is reached within $60-80 \mathrm{~min}$ and is dose-related. ${ }^{10,11}$ Nausea, dizziness, headache, insomnia, fatigue, and nasopharyngitis represent the most commonly treatment-related adverse effects of DPX, ${ }^{12}$ which were also dose-dependent and mostly synchronized with the pharmacokinetic profile of DPX. ${ }^{7}$

Zein is used as a matrix for nano/and micro-structured drug delivery systems. ${ }^{13-16}$ Zein contains high percentage of hydrophobic amino acids that renders Zein insoluble under physiological conditions that cause aggregation into colloidal particles. The hydrophobic residues of Zein polymer (as lucine, phenylalanine, etc.) allows the self-association of Zein protein into bodies that are stably retained in membrane vesicles. ${ }^{13-16}$ The hydrophobic nature of Zein and excellent biocompatibility allows its use to design and sustain the release of loaded drugs. ${ }^{17,18}$

Alpha-lipoic acid (ALA) is a powerful antioxidant that is also known as acetate replacing factor. ALA improves sexual function and used in the treatment of diabetic impotence due to its antioxidant activity. ${ }^{19-23}$ Recently, ALA has been used as a formulation excipient to improve the delivery and efficacy of drugs. ${ }^{24,25}$
The aim of this study was to use Zein and ALA to encapsulate DPX and utilize mathematical experimental design to optimize formulation parameters for the preparation of DPX-Zein-ALA NPs. The objective is to control DPX release utilizing Zein as a retarding polymer which increasing its residence time in the body and hence improving bioavailability of DPX after oral administration to decrease its therapeutic dose and hence decrease the incidence of its adverse effects.

\section{Materials and methods}

\section{Materials}

DPX was a gift from Spimaco Addwaeih (Riyadh, KSA). ALA, Zein, polyvinyl alcohol (PVA), acetonitrile and methanol were purchased from Sigma-Aldrich Corporation (St. Louis, Missouri, USA).

\section{Experimental design of DPX formulations} Based on preliminary data, the factors of ALA percentage in Zein $\left(\mathrm{X}_{1}\right)$, PVA percentage concentration $\left(\mathrm{X}_{2}\right)$ and stirring rate $\left(\mathrm{X}_{3}\right)$ were selected to study their effect on the particle size $\left(\mathrm{Y}_{1}\right)$, zeta potential $\left(\mathrm{Y}_{2}\right)$, initial DPX release $\left(\mathrm{Y}_{3}\right)$ and cumulative DPX release $\left(\mathrm{Y}_{4}\right)$ of the prepared formulations. The Box-Behnken design was suggested for the development of DPX formulations using Statgraphics Centurion XV version 15.2.05 software (StatPoint Technologies Inc., Warrenton, VA, USA). The goals for the investigated dependent variables of the experimental design were set to minimize $Y_{1}$ and maximize $Y_{2}, Y_{3}$, and $Y_{4}$. The independent variables levels and the dependent variables constraints are shown in Table 1.

Table I Independent $\left(X_{1}-X_{3}\right)$ and dependent $\left(Y_{1}-Y_{4}\right)$ variables of DPX-Zein-ALA nanoparticles formulations utilized in Box-Behnken design

\begin{tabular}{|c|c|c|c|c|}
\hline \multirow[t]{2}{*}{ Independent Variables } & \multirow[t]{2}{*}{ Unit } & \multicolumn{3}{|c|}{ Levels } \\
\hline & & -1 & $\mathbf{0}$ & $\mathbf{I}$ \\
\hline Percentage of ALA in Zein $\left(X_{1}\right)$ & $\%$ & 15 & 20 & 25 \\
\hline Percentage of PVA $\left(\mathrm{X}_{2}\right)$ & $\%$ & 0.5 & 1 & 1.5 \\
\hline Stirring rate $\left(X_{3}\right)$ & rpm & 800 & 1000 & 1200 \\
\hline \multirow[t]{2}{*}{ Dependent variables } & Unit & \multicolumn{3}{|c|}{ Constraints } \\
\hline & & Low & High & Goal \\
\hline Particle size $\left(\mathrm{Y}_{\mathrm{I}}\right)$ & $\mathrm{nm}$ & 148.6 & 206.8 & Minimize \\
\hline Zeta potential $\left(\mathrm{Y}_{2}\right)$ & $\mathrm{mV}$ & 0.294 & 19.1 & Maximize \\
\hline Initial DPX release after $\mathrm{Ih}\left(\mathrm{Y}_{3}\right)$ & $\%$ & 18.09 & 35.67 & Maximize \\
\hline Cumulative DPX release after $24 \mathrm{~h}\left(\mathrm{Y}_{4}\right)$ & $\%$ & 79.05 & 97.65 & Maximize \\
\hline
\end{tabular}

Abbreviations: DPX, dapoxetine; ALA, alpha lipoic acid; PVA, polyvinyl alcohol. 


\section{Preparation of DPX-loaded NPs}

Fifteen different formulations of DPX-loaded NPs were prepared as previously reported. ${ }^{24}$ Briefly, $30 \mathrm{mg}$ of DPX, and the specified weight of Zein and ALA as described in Table 2 were stirred in $30 \mathrm{~mL}$ methanol at $1000 \mathrm{rpm}$ at room temperature until completely solubilized. The methanolic solution was gradually added to $45 \mathrm{~mL}$ of an aqueous solution of PVA $(0.5-1.5 \% \mathrm{w} / \mathrm{v})$ and stirred for $4 \mathrm{hrs}$, then rotated in a rotary evaporator until complete evaporation of the methanol. The colloidal NPs dispersion was centrifuged at 20,000 rpm for 45 mins at $8{ }^{\circ} \mathrm{C}$ and washed with deionized water, then lyophilized using freeze dryer Alpha1-2/LDPlus (Martin Christ, Osterode am Harz, Germany) for $72 \mathrm{hrs}$. Mannitol (5\% w/v) was added to the colloidal dispersion as a cryoprotectant and finally stored until fully characterized.

\section{DPX-loaded NPs characterization}

Particle size and zeta potential analysis

Samples of the prepared NPs formulations were diluted with 20 times their volume and vortexed for $1 \mathrm{~min}$ and evaluated for particle size, size distribution and zeta potential using Malvern zetasizer nano zsp analyzer (Malvern
Panalytical, Enigma Business Park, Malvern, United Kingdom).

\section{DPX encapsulation efficiency, DPX loading and yield percent}

DPX encapsulation efficiency percent (EE \%) was determined by dissolving accurately weighed amount of the NPs formulation in methanol, then sonicated and filtered. The encapsulated DPX in the formulation was measured by high-performance liquid chromatography (HPLC). EE $\%$, DPX loading $\%$ and yield $\%$ were calculated according to Equations (1)-(3)

$$
\mathrm{EE} \%=\left(\frac{\text { Amount of drug in the formula }}{\text { Amount of drug initially added }}\right) \times 100
$$

DPX Loading $\%=\left(\frac{\text { Drug mass in nanoparticles }}{\text { mass of nanoparticles }}\right) \times 100$

$$
\text { Yield } \%=\left(\frac{\text { mass of nanoparticles }}{\text { total mass of formula components }}\right) \times 100
$$

Table 2 Formulation variables $\left(X_{1}-X_{3}\right)$ of DPX-Zein-ALA nanoparticles and their observed responses $\left(Y_{1}-Y_{4}\right)$ as suggested by

\begin{tabular}{|c|c|c|c|c|c|c|c|}
\hline \multirow[t]{2}{*}{ Run \# } & \multicolumn{3}{|c|}{ Independent variables } & \multicolumn{4}{|c|}{ Dependent variables* } \\
\hline & $\begin{array}{l}\text { Percentage of } \\
\text { ALA in Zein }\left(X_{1}\right)\end{array}$ & $\begin{array}{l}\text { Percentage of } \\
\text { PVA }\left(\mathbf{X}_{2}\right)\end{array}$ & $\begin{array}{l}\text { Stirring } \\
\text { rate }\left(X_{3}\right)\end{array}$ & $\begin{array}{l}\text { Particle } \\
\text { size }\left(Y_{1}\right)\end{array}$ & $\begin{array}{l}\text { Zeta } \\
\text { potential } \\
\left(\mathbf{Y}_{2}\right)\end{array}$ & $\begin{array}{l}\text { Initial DPX release } \\
\text { after } \operatorname{Ih}\left(Y_{3}\right)\end{array}$ & $\begin{array}{l}\text { Cumulative DPX } \\
\text { release }\left(\mathbf{Y}_{4}\right)\end{array}$ \\
\hline DN-I & 15 & 1.5 & 1000 & 155.6 & 17.3 & 29.68 & 97.32 \\
\hline DN-2 & 15 & 0.5 & 1000 & 159.7 & 19.1 & 31.34 & 97.65 \\
\hline DN-3 & 20 & 0.5 & 800 & 168.9 & 15.2 & 24.34 & 93.76 \\
\hline DN-4 & 25 & 1.0 & 800 & 205.7 & $0.4 \mathrm{I}$ & 19.1 & 87.61 \\
\hline DN-5 & 20 & 1.5 & 800 & 163.8 & 10.6 & 26.1 & 96.99 \\
\hline DN-6 & 25 & 0.5 & 1000 & 206.8 & $0.4 \mathrm{I}$ & 18.09 & 79.05 \\
\hline DN-7 & 20 & 0.5 & 1200 & 150.1 & 15.1 & 33.45 & 96.95 \\
\hline DN-8 & 15 & 1.0 & 1200 & 148.6 & 17.9 & 35.67 & 97.03 \\
\hline DN-9 & 25 & 1.5 & 1000 & 194.7 & 0.29 & 22.7 & 88.2 \\
\hline DN-IO & 25 & 1.0 & 1200 & 196.9 & 0.39 & 20.1 & 89.4 \\
\hline DN-II & 20 & 1.5 & 1200 & 160.2 & 13.6 & 30.21 & 96.55 \\
\hline $\mathrm{DN}-12$ & 15 & 1.0 & 800 & 167.3 & 18.0 & 23.54 & 93.21 \\
\hline DN-I3 & 20 & 1.0 & 1000 & I79.1 & 14.6 & 28.48 & 89.54 \\
\hline $\mathrm{DN}-14$ & 20 & 1.0 & 1000 & 177.4 & 14.3 & 29.36 & 91.11 \\
\hline DN-15 & 20 & 1.0 & 1000 & 176.9 & 14.7 & 27.12 & 92.89 \\
\hline
\end{tabular}
Box-Behnken design

Note: *The observed values of $Y_{1}, Y_{2}, Y_{3}$ and $Y_{4}$ represent the means of three determinations; standard deviations were $<5 \%$ of the mean and thus were omitted from the table.

Abbreviations: DPX, dapoxetine; ALA, alpha lipoic acid; $X_{1}$, percentage of alpha lipoic acid in Zein; $X_{2}$, percentage of polyvinyl alcohol; $X_{3}$, stirring rate; $Y_{1}$, particle size $(\mathrm{nm}) ; \mathrm{Y}_{2}$, zeta potential $(\mathrm{mV}) ; \mathrm{Y}_{3}$, initial DPX release after $\mathrm{Ih}(\%) ; \mathrm{Y}_{4}$, cumulative DPX release after $24 \mathrm{~h}(\%)$. 


\section{In vitro release of DPX-loaded NPs}

In vitro release study was investigated utilizing Franz diffusion cell (automated diffusion system, Microette Plus, Hanson research, Chatsworth, CA, USA) as previously described. ${ }^{26}$ Briefly, the specified weight of DPX-loaded NPs in the donor compartment above the diffusion membrane $(0.1 \mu \mathrm{m}$, PALL Corporation, NY, USA) was allowed to diffuse into phosphate-buffered saline $\mathrm{pH} 7.0$ in the receptor compartment. Samples were withdrawn at predetermined time intervals for $48 \mathrm{~h}$ and analyzed for DPX using an Agilent 1200 HPLC system with a quaternary pump, autosampler and diode-array detector (DAD) (Agilent Technologies, Waldbronn, Germany). The separation process was carried out utilizing an Agilent Zorbax Eclipse Plus C18 column, $3.5 \mu \mathrm{m}$, $4.6 \times 250 \mathrm{~mm}$ (Agilent Technologies, Santa Clara, California, USA) and maintained at $40{ }^{\circ} \mathrm{C}$. The mobile phase was acetonitrile: phosphate buffer $\left(0.02 \mathrm{M} \mathrm{KH}_{2} \mathrm{PO}_{4}\right.$ adjusted to $\mathrm{pH} 3$ with orthophosphoric acid) (45: 55, v/v), with a flow rate of $1 \mathrm{~mL} / \mathrm{min}$, and peaks were detected at $210 \mathrm{~nm}$. The injection volume was $50 \mu 1$. Methanol was used in the preparation of the stock solution of DPX in the concentration of $2000 \mu \mathrm{g} / \mathrm{mL}$. The range of DPX concentrations was $8-200 \mu \mathrm{g} / \mathrm{mL}$ and used as working standards in the assay.

\section{Optimization of DPX-loaded NPs formulations}

Results obtained from the prepared 15 formulations, according to the design, were statistically analyzed with ANOVA and multiple response optimization using Statgraphics software. The predicted optimum formulation was prepared and evaluated and compared to the practically prepared optimum formulation for validation of the results. The optimized DPX-loaded NPs formulation was also examined for particle size, zeta potential and morphology scanning electron microscopy (SEM) and transmission electron microscopy (TEM).

\section{Scanning electron microscopy (SEM)}

The surface of the optimized DPX-loaded NPs was explored after lyophilization using SEM. The sample was mounted on metal stubs with conductive silver paint, sputtered with gold and investigated using SEM (Philips XL30; FEI, Hillsboro, OR, USA).

\section{Transmission electron microscopy (TEM)}

A sample of the optimized DPX-loaded NPs was exposed to a TEM (Model JEM-1230, JOEL, Tokyo, Japan). A drop of the diluted NPs dispersion was added onto a microscope grid, stained with $1 \%$ phosphotungstic acid and then dried before investigation.

\section{Pharmacokinetics evaluation on healthy human volunteers}

The pharmacokinetic parameters of the optimized DPXloaded NPs were evaluated and compared with the marketed DPX tablet, (SPIMACO, Al-Qassim, Saudi Arabia) (reference), following oral administration of a single dose $(30 \mathrm{mg}$ ) by healthy male volunteers. An open-label, singledose, randomized, one-period, parallel design was used in which two weeks of screening preceded $24 \mathrm{~h}$ study periods as previously described. ${ }^{24}$ Briefly, the single-dose investigation was performed in the Egyptian Research and Development Company (ERDC), Cairo, Egypt. The study protocol was approved by the Research Ethical Committee (Protocol code: 0569/452) in agreement with the Declaration of Helsinki and the International Conference on "Harmonisation of Good Clinical Practices". Written informed consents were obtained before volunteers were allowed to participate in the study. The prepared optimized DPX-loaded NPs and the commercial DPX tablet were administered orally $(30 \mathrm{mg}$, DPX). Twelve Egyptian male volunteers (25-43 years) participated in this study and were divided into two groups (6 each). Blood samples $(5 \mathrm{~mL})$ were collected at $0,0.16$, $0.25,0.5,0.75,1,1.25,1.5,2,2.5,3,4,6,8,12$, and $24 \mathrm{~h}$ and centrifuged at $3500 \mathrm{rpm}$ for $10 \mathrm{~min}$.

\section{Chromatographic conditions for DPX analysis in human plasma}

HPLC-MS/MS analytical method was developed at the ERDC laboratories for the determination of DPX in human plasma. ${ }^{24}$ Assay linearity was verified for DPX at $2-500 \mathrm{ng} / \mathrm{mL}$ with a regression coefficient $\left(\mathrm{R}^{2}=0.994\right)$. The HPLC-MS/MS system consisted of HPLC Agilent series 1200 (Agilent Technologies Deutschland GmbH, Waldbronn, Germany) system with a mass spectrometer detector (Agilent 6420) Triple Quad G1311A quaternary pump, G1329A autosampler, G1322A vacuum degasser, and mass hunter software. A mixture of $75 \%$ acetonitrile: $25 \%$ buffer (ammonium formate $20 \mathrm{mM}+0.2 \%(\mathrm{v} / \mathrm{v})$ formic acid in water) was used as a mobile phase at a flow rate of $0.35 \mathrm{~mL} / \mathrm{min}$. The reversed-phase column Intersil ODS $-3(4.6 \mathrm{~mm} \times 50 \mathrm{~cm}$, dp $5 \mu \mathrm{m}$ SigmaAldrich, USA) was temporized at $25{ }^{\circ} \mathrm{C}$. Sildenafil was used as an internal standard (IS). 


\section{Pharmacokinetic data analysis}

Noncompartmental analysis was utilized to calculate the pharmacokinetic $(\mathrm{PK})$ parameters using Kinetica ${ }^{\circledR}$ software (version 4; Thermo Electron Corp., Waltham, MA, USA). The difference between the two investigated groups in terms of drug plasma concentration was calculated by two-way ANOVA followed by Sidak's multicomparison test using GraphPad Prism 6 Software, Inc. (CA, USA). Unpaired $t$-test (two-tailed) was used to determine the significance between the pharmacokinetic parameters. The peak plasma concentration of the drug $\left(\mathrm{C}_{\max }\right)$, the time required for drug to reach the maximum plasma concentration $\left(\mathrm{t}_{\max }\right)$, The area under the time-concentration curve (AUC), elimination rate constant $\left(\mathrm{K}_{\mathrm{el}}\right)$ and mean drug residence time (MRT) were calculated from which the relative bioavailability $\left[\left(\mathrm{AUC}_{\text {test }} / \mathrm{AUC}_{\text {reference }}\right)\right.$ $\times 100$ ] was determined.

\section{Results and discussions}

The objective of this study was optimizing DPX-loaded NPs to improve its absorption and maximize its oral bioavailability. The predefined critical quality features of the DPX-loaded NPs were particle size, zeta potential, and DPX release pattern. Minimizing the particle size of the prepared NPs would allow for increased permeability and absorption via the mucosal membranes. Therefore, we conducted studies to optimize the factors affecting NPs formulation to minimize the nanoparticle size, maximize zeta potential, while maximizing drug release. We then verified the efficiency of the optimized DPX-loaded NPs by conducting pharmacokinetic studies on human volunteers after oral administration of a single dose and compared the result with marketed DPX tablet.

\section{DPX-loaded NPs formulation and characterization}

Particle size and zeta potential are key parameters for evaluation of NPs stability and efficiency which influence the biopharmaceutical feature of NPs.

\section{Particle size $\left(\mathrm{Y}_{\mathrm{I}}\right)$}

As reported previously in several studies, the physicochemical properties of NPs (nano-size range of the particles) rather than the drug itself, determines the release profile and absorption of the drug. ${ }^{27-29}$ Due to their nano-size range, NPs have large surface areas available for absorption via the epithelial surfaces. ${ }^{30,31}$

Table 2 shows the variabilities in the size of the prepared NPs formulations that ranged from 148.6 to $206.8 \mathrm{~nm}$ for DN-8 and DN-6, with respect to changes of the investigated factors, with the results displayed in Table 3. It is worth to mention that the polydispersity index of the formulations did not exceed 0.3 which

Table 3 Statistical analysis of variance (ANOVA) of the responses $\left(\mathrm{Y}_{1}-\mathrm{Y}_{4}\right)$ results

\begin{tabular}{|c|c|c|c|c|c|c|c|c|}
\hline \multirow[t]{2}{*}{ Factors } & \multicolumn{2}{|c|}{ Particle size $\left(Y_{1}\right)$} & \multicolumn{2}{|c|}{ Zeta potential $\left(\mathbf{Y}_{2}\right)$} & \multicolumn{2}{|c|}{ Initial DPX release after $I \mathrm{~h}\left(\mathrm{Y}_{3}\right)$} & \multicolumn{2}{|c|}{$\begin{array}{l}\text { Cumulative DPX release after } 24 \mathrm{~h} \\
\left(\mathrm{Y}_{4}\right)\end{array}$} \\
\hline & Estimate & p-Value & Estimate & p-Value & Estimate & p-Value & Estimate & p-Value \\
\hline$X_{1}$ & 43.225 & $0.0001 *$ & -17.703 & $0.000 I^{*}$ & -10.06 & $0.000 I^{*}$ & -10.238 & $0.0032 *$ \\
\hline $\mathrm{X}_{2}$ & -2.8 & 0.3123 & -2.002 & $0.0189 *$ & 0.368 & 0.6257 & 2.913 & 0.1923 \\
\hline $\mathrm{X}_{3}$ & -12.475 & $0.004 I^{*}$ & 0.693 & 0.2903 & 6.588 & $0.0002^{*}$ & 2.09 & 0.3290 \\
\hline$x_{1}{ }^{2}$ & 20.275 & $0.0027^{*}$ & -9.704 & $0.000 I^{*}$ & -6.79 & $0.0013^{*}$ & -4.875 & 0.1473 \\
\hline$X_{1} X_{2}$ & -4.0 & 0.3079 & 0.842 & 0.3565 & 3.135 & $0.0259 *$ & 4.74 & 0.1435 \\
\hline$X_{1} X_{3}$ & 4.95 & 0.2192 & 0.041 & 0.9625 & -5.565 & $0.0026 *$ & -1.015 & 0.7257 \\
\hline$x_{2}^{2}$ & -17.475 & $0.0050 *$ & -0.810 & 0.3907 & 1.055 & 0.3576 & 3.625 & 0.2587 \\
\hline$X_{2} X_{3}$ & 7.6 & 0.0836 & 1.545 & 0.1214 & -2.5 & 0.0546 & -1.815 & $0.536 \mathrm{I}$ \\
\hline$x_{3}^{2}$ & -16.625 & $0.0062^{*}$ & -1.001 & 0.2984 & -0.645 & 0.5629 & 6.14 & 0.0834 \\
\hline $\mathrm{R}^{2}$ & \multicolumn{2}{|l|}{98.8063} & \multicolumn{2}{|l|}{99.529} & \multicolumn{2}{|l|}{98.7042} & \multicolumn{2}{|l|}{89.9672} \\
\hline Adj. $R^{2}$ & \multicolumn{2}{|l|}{96.6577} & \multicolumn{2}{|l|}{98.6813} & \multicolumn{2}{|l|}{96.3719} & \multicolumn{2}{|l|}{71.9082} \\
\hline SEE & \multicolumn{2}{|l|}{3.52484} & \multicolumn{2}{|l|}{0.828797} & \multicolumn{2}{|l|}{ I.00074 } & \multicolumn{2}{|l|}{2.7339} \\
\hline MAE & \multicolumn{2}{|l|}{1.75667} & \multicolumn{2}{|l|}{0.409478} & \multicolumn{2}{|l|}{0.462667} & \multicolumn{2}{|l|}{1.39367} \\
\hline
\end{tabular}

Note: *Significant effect of factors on individual responses.

Abbreviations: DPX, dapoxetine; ALA, alpha lipoic acid; $X_{1}$, percentage of alpha lipoic acid in Zein; $X_{2}$, percentage of polyvinyl alcohol; $X_{3}$, stirring rate; $Y_{1}$, particle size (nm); $Y_{2}$, zeta potential $(\mathrm{mV}) ; Y_{3}$, initial DPX release after I h (\%); $Y_{4}$, cumulative DPX release after $24 \mathrm{~h}(\%) ; X_{1} X_{2}, X_{1} X_{3}, X_{2} X_{3}$, the interaction term between the factors; $X_{1} X_{1}$, $\mathrm{X}_{2} \mathrm{X}_{2}$, and $\mathrm{X}_{3} \mathrm{X}_{3}$ are the quadratic terms between the factors; $\mathrm{R}^{2}, \mathrm{R}$-squared; Adj-R ${ }^{2}$, Adjusted R-squared; SEE, standard error of estimate; and MAE, Mean absolute error. 
indicates unimodal distribution of the size and good uniformity of the prepared formulations.

Two-way ANOVA analyses showed a significant synergistic effect of the percentage of ALA in Zein $\left(\mathrm{X}_{1}\right)$ on the particle size $\left(\mathrm{Y}_{1}\right)$ with a $p$-value of 0.0001 . While the stirring rate $\left(\mathrm{X}_{3}\right)$ was found to have a significant antagonistic effect on $\mathrm{Y}_{1}$ with a $p$-value of 0.0041 . Also, it was noticed that the quadratic term of $X_{1}$ had a significant synergistic effect on $\mathrm{Y}_{1}$ with a $p$-value of 0.0027 . Finally, it was noticed that $Y_{1}$ was significantly affected by the quadratic term of $\mathrm{X}_{2}$ and $\mathrm{X}_{3}$ with $p$-values of 0.0050 and 0.0062 , respectively. The prediction model to correlate variables with the obtained sizes is shown in Equation (4).

$$
\begin{aligned}
Y_{1}= & 116.275-13.5725 X_{1}+45.1 X_{2}+0.29694 X_{3} \\
& +0.4055 X_{1}^{2}-0.8 X_{1} X_{2}+0.0025 X_{1} X_{3} \\
& -34.95 X_{2}^{2}+0.038 X_{2} X_{3}-0.0002 X_{3}^{2}
\end{aligned}
$$

We observed that increasing ALA percentage in the polymer content of the formulations led to a significant increase in the particle size of the NPs as observed in
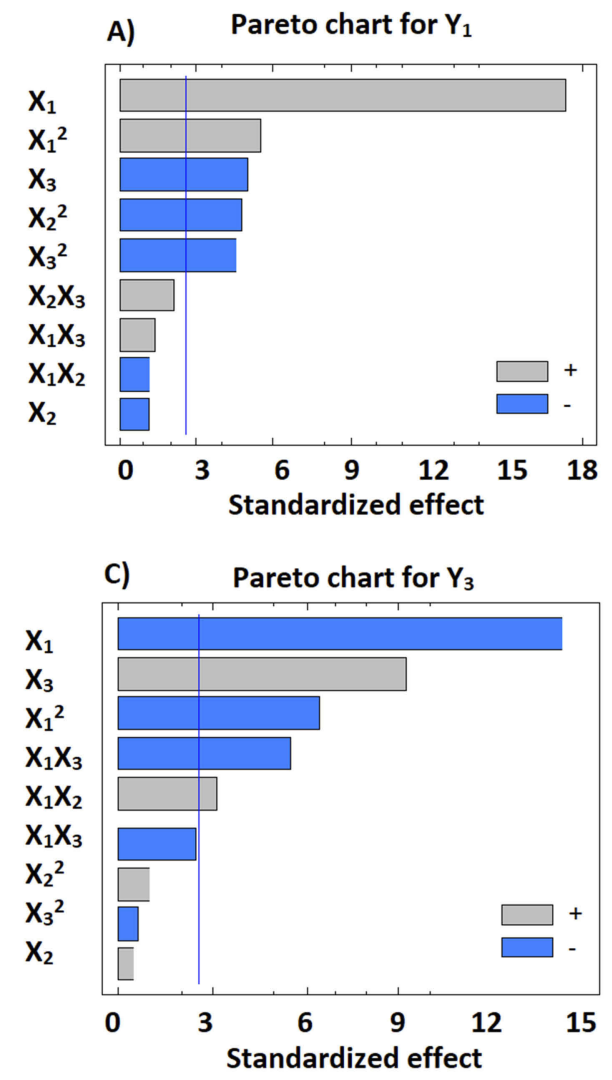

the formulations DN-4, DN-6, DN-9, and DN-10. This may be explained by the formation of aggregates due to interactions between ALA and Zein matrix, consistent with a previously reported study of ALA addition to a positively charged chitosan. ${ }^{32}$ Conversely, increasing the percentage of Zein in the polymeric matrix resulted in the formation of smaller size NPs, likely due to the presence of charged amino acids in the Zein structure. ${ }^{33,34}$ At $\mathrm{pH}$ 7.2, the protein molecules aggregated into small size particles with reduced void spaces, enhancing NPs formation and hindering large aggregation via acceleration of thiol-disulfide interchange reaction. ${ }^{16}$ Another possible explanation may be related to the structural configuration of hydrophilic and hydrophobic regions on Zein surface. Zein molecules associated into an elongated prism-like shape with hydrophobic sides and hydrophilic tops and bottoms, ${ }^{35}$ allowing Zein molecules to associate in a side-by-side manner to form many small NPs. This direct relationship between $\mathrm{X}_{1}$ and the particle size $\left(\mathrm{Y}_{1}\right)$ are presented in the Pareto chart and response surface plots of $\mathrm{Y}_{1}$ (Figures $1 \mathrm{~A}$ and $2 \mathrm{~A}, \mathrm{~B}$ ).
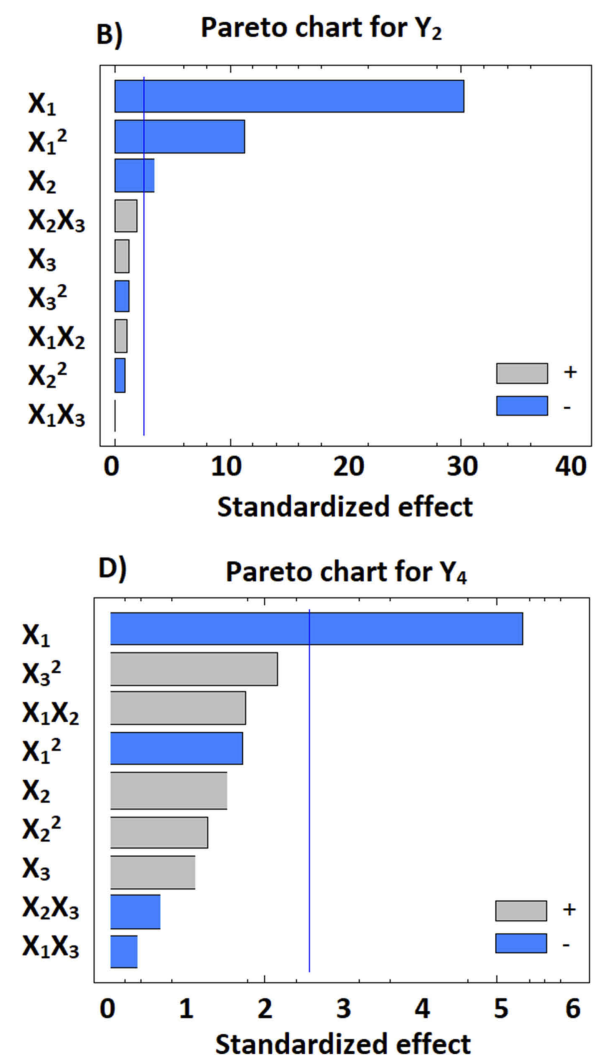

Figure I Standardized Pareto charts showing the significance of $X_{1}, X_{2}$ and $X_{3}$ and their combined effects on $Y_{1}(\mathbf{A}) ; Y_{2}(B) ; Y_{3}(\mathbf{C})$ and $Y_{4}(\mathbf{D})$. Abbreviations: $X_{1}$, percentage of alpha lipoic acid in zein; $X_{2}$, polyvinyl alcohol \% concentration; $X_{3}$, stirring rate; $Y_{1}$, particle size (nm); $Y_{2}$, zeta potential (mV); $Y_{3}$, initial permeation after $\mathrm{I} \mathrm{h}(\%) ; \mathrm{Y}_{4}$, cumulative permeation after $24 \mathrm{~h}(\%)$. 

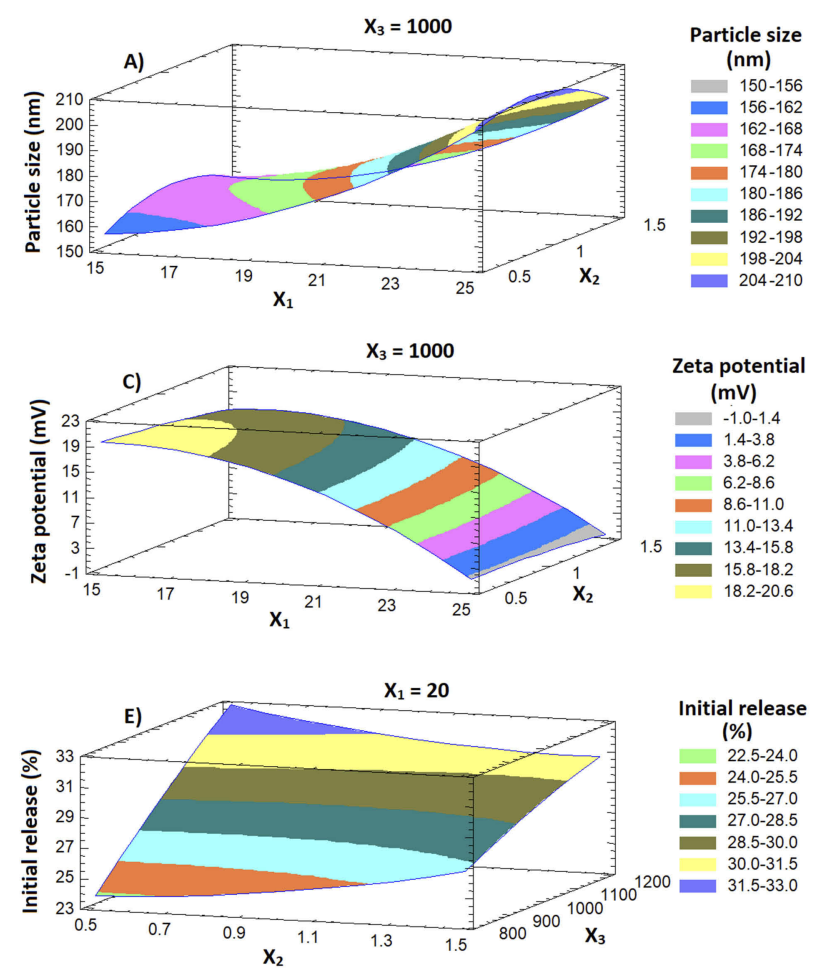
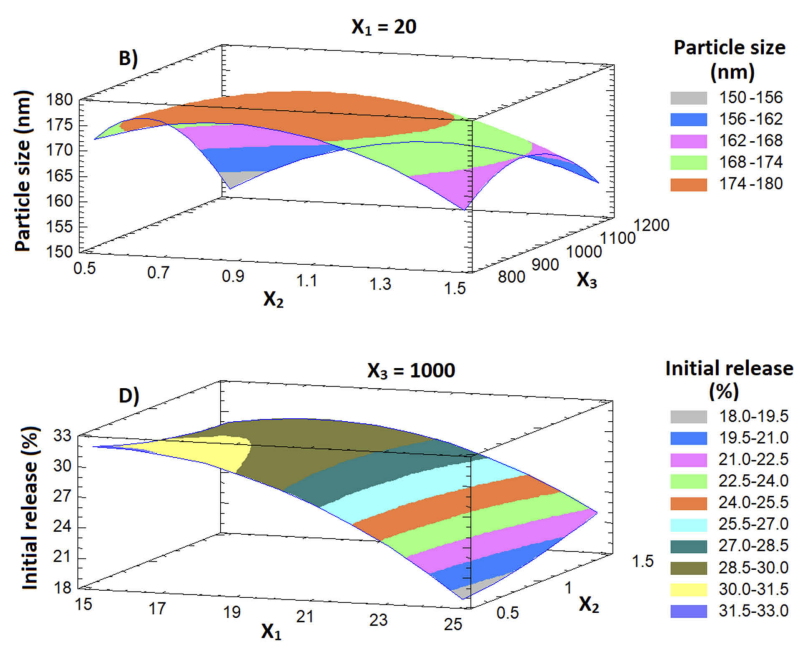

Initial release (\%) 18.0-19.5 - 19.5-21.0 21.0-22.5 22.5-24.0 $24.0-25.5$ $25.5-27.0$ 27.0-28.5 $28.5-30.0$
$30.0-31.5$ 31.5-33.0

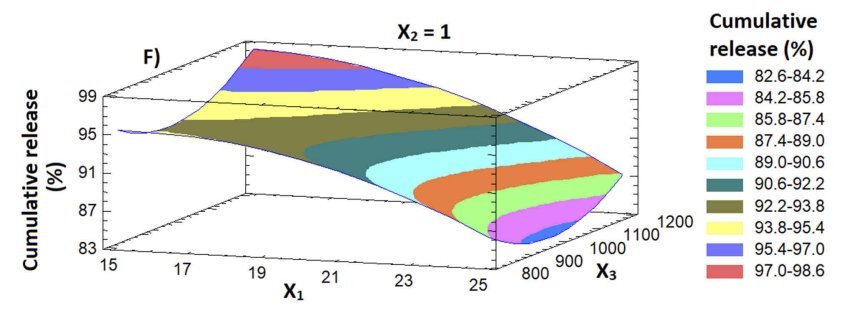

Figure $23 D$ response surface plots showing the effects of $X_{1}, X_{2}$ and $X_{3}$ on the investigated dependent variables $Y_{1}(\mathbf{A}$ and $\mathbf{B})$; $Y_{2}(\mathbf{C})$; $Y_{3}(\mathbf{D}$ and $\mathbf{E})$ and $Y_{4}(\mathbf{F})$. Abbreviations: DPX, dapoxetine; $X_{1}$, percentage of alpha lipoic acid in Zein; $X_{2}$, polyvinyl alcohol \% concentration; $X_{3}$, stirring rate; $Y_{1}$, particle size (nm); $Y_{2}$, zeta potential $(\mathrm{mV}) ; \mathrm{Y}_{3}$, initial release after I $\mathrm{h}(\%) ; \mathrm{Y}_{4}$, cumulative release after $24 \mathrm{~h}(\%)$.

We observed an inverse relationship between the stirring rate $\left(\mathrm{X}_{3}\right)$ and the average particle size $\left(\mathrm{Y}_{1}\right)$. The particle size increased from 150.1 to $168.9 \mathrm{~nm}$ in DN-7 and DN-3, respectively when the stirring rate was decreased from 1200 to $800 \mathrm{rpm}$ at an equal level of $\mathrm{X}_{1}$ and $\mathrm{X}_{2}$. Also, the particle size increased from 196.9 to $205.7 \mathrm{~nm}$ in DN-10 and DN-4, respectively by decreasing $X_{3}$ from 1200 to $800 \mathrm{rpm}$ at the same level of $X_{1}$ and $X_{2}$. We also observed an increase of $\mathrm{Y}_{1}$ from 148.6 to $167.3 \mathrm{~nm}$ for DN-8 and DN-12, respectively with a decrease in $\mathrm{X}_{3}$ from 1200 to $800 \mathrm{rpm}$ at the same level of $X_{1}$ and $X_{2}$. This finding could be explained by increasing the shearing action and reducing the tendency of a collision between the formed NPs and decreasing the possibility for aggregation that leads to smaller particle size. ${ }^{36-38}$

\section{Zeta potential $\left(\mathrm{Y}_{2}\right)$}

Zeta potential represents a key indicator for the stability of the colloidal dispersions. The values of zeta potential of all $\mathrm{NP}$ formulations $\left(\mathrm{Y}_{2}\right)$ was in the range from $0.29 \mathrm{mV}$ for DN-9 to $19.1 \mathrm{mV}$ for DN-2 (Table 2). In general, all formulations were considerably stable except the formulations containing a high percentage of ALA $(25 \%)$. It was clear that $\mathrm{X}_{1}$ (Percentage of ALA in Zein) and $\mathrm{X}_{2}$ (percentage of PVA) were the main factors responsible for the difference in the zeta potential of DPX-loaded NPs as shown in Figures 1B and 2C. Multiple regression analysis indicated that both $\mathrm{X}_{1}$ and $\mathrm{X}_{2}$ had significant inverse effects on the zeta potential $\left(\mathrm{Y}_{2}\right)$ with a more predominant effect on $\mathrm{X}_{1}$ with $p$-values of 0.0001 and 0.0189 , respectively (Table 3). The prediction Equation (5) of zeta potential value is:

$$
\begin{aligned}
Y_{2}= & -30.0548+5.804 \mathrm{X}_{1}-9.8487 \mathrm{X}_{2}+0.0186 \mathrm{X}_{3} \\
& -0.19408 \mathrm{X}_{1}^{2}+0.1683 \mathrm{X}_{1} \mathrm{X}_{2}+0.00002 \mathrm{X}_{1} \mathrm{X}_{3} \\
& -1.6207 \mathrm{X}_{2}^{2}+0.0077 \mathrm{X}_{2} \mathrm{X}_{3}-0.00001 \mathrm{X}_{3}^{2}
\end{aligned}
$$

It was evident that an increased percentage of ALA in the polymeric matrix led to markedly decreased in the zeta potential of the prepared NPs. The zeta potential value of formulations containing $15 \%$ of ALA is close to $20 \mathrm{mV}$ while the formulations containing $25 \%$ of ALA is less than 1. An increase in $X_{1}$ from 15 to $25 \%$, at the same level of $\mathrm{X}_{2}$ and $\mathrm{X}_{3}$, led to a decrease in zeta potential from 17.3 to $0.29 \mathrm{mV}$ for DN-1 and DN-9, respectively. The same finding was observed in $\mathrm{DN}-2$ and $\mathrm{DN}-6$ by decreasing the zeta potential from 19.1 to $0.41 \mathrm{mV}$, respectively. Also, 
this finding could be confirmed by the decrease of $\mathrm{Y}_{2}$ from 18.0 to $0.41 \mathrm{mV}$ for $\mathrm{DN}-12$ and $\mathrm{DN}-4$, respectively. We attribute these observations to increased adsorption of ALA on the surface of NPs (observed with zeta potential measurement) that could neutralize the positive charges of Zein NPs. The positive charge on Zein NPs was found to decrease when the percentage of ALA increased in the polymeric matrix. The adsorption of ALA with its anionic free fatty acids on the formed cationic Zein surfaces could neutralize their positive charge. ${ }^{39}$ Nishiura also explained this finding to the vicinity of the dissociated carboxyl groups of ALA that could shield the positive charge on the Zein-loaded NPs surface. ${ }^{40}$

Despite a lesser effect of $X_{2}$ than $X_{1}$ on $Y_{2}$, it was found that increasing $X_{2}$ from 0.5 to $1.5 \%$, at the same level of $X_{1}$ and $X_{2}$, led to the decrease in zeta potential from 19.1 to $17.3 \mathrm{mV}$ for $\mathrm{DN}-2$ and $\mathrm{DN}-1$, respectively. The same finding was observed in DN-7 and DN-11 by decreasing the zeta potential from 15.1 to $13.6 \mathrm{mV}$, respectively. Also, this finding could be confirmed by the decrease of $\mathrm{Y}_{2}$ from 15.2 to $10.6 \mathrm{mV}$ for DN-3 and DN5 , respectively. This observation could be attributed to incomplete hydrolysis of the starting material resulting in a number of acetic groups that are capable of ionizing and reducing the positive charge that affects zeta potential of the prepared nanoparticles. ${ }^{41}$

DPX EE \%, DPX loading and yield percentagepercent The data for DPX EE\% showed no significant change in $\mathrm{EE} \%$ among the prepared formulations with an average value of $34.35 \pm 4.66 \%$. DPX is mainly charged at physiological $\mathrm{pH}$ with its $\mathrm{pKa}$ of 8.6. The protonation of DPX is attributed to the elevated aqueous solubility $(68 \mathrm{mg} / \mathrm{mL})$ that contributes to the reduction of $\mathrm{EE} \%$. In addition, results revealed that the prepared formulations showed average DPX loading \% and yield \% of $18.9 \%$ and $54.52 \%$, respectively.

\section{In vitro release behavior of DPX from NP} formulations $\left(Y_{3}\right.$ and $\left.Y_{4}\right)$

This study was conducted to predict the in vivo behavior of the nanoparticle. The in vitro release of DPX from the prepared NPs formulations (DN-1 to DN-15) showed a biphasic form with an initial rapid release followed by a controlled release phase (Figure 3). The initial release after $1 \mathrm{hr}$ range from $18.09 \%$ with DN-6 to $35.67 \%$ with DN-8 (Table 2). Whereas, the cumulative \% of DPX released after 24 hrs showed DN-2 to have the most release (97.65)
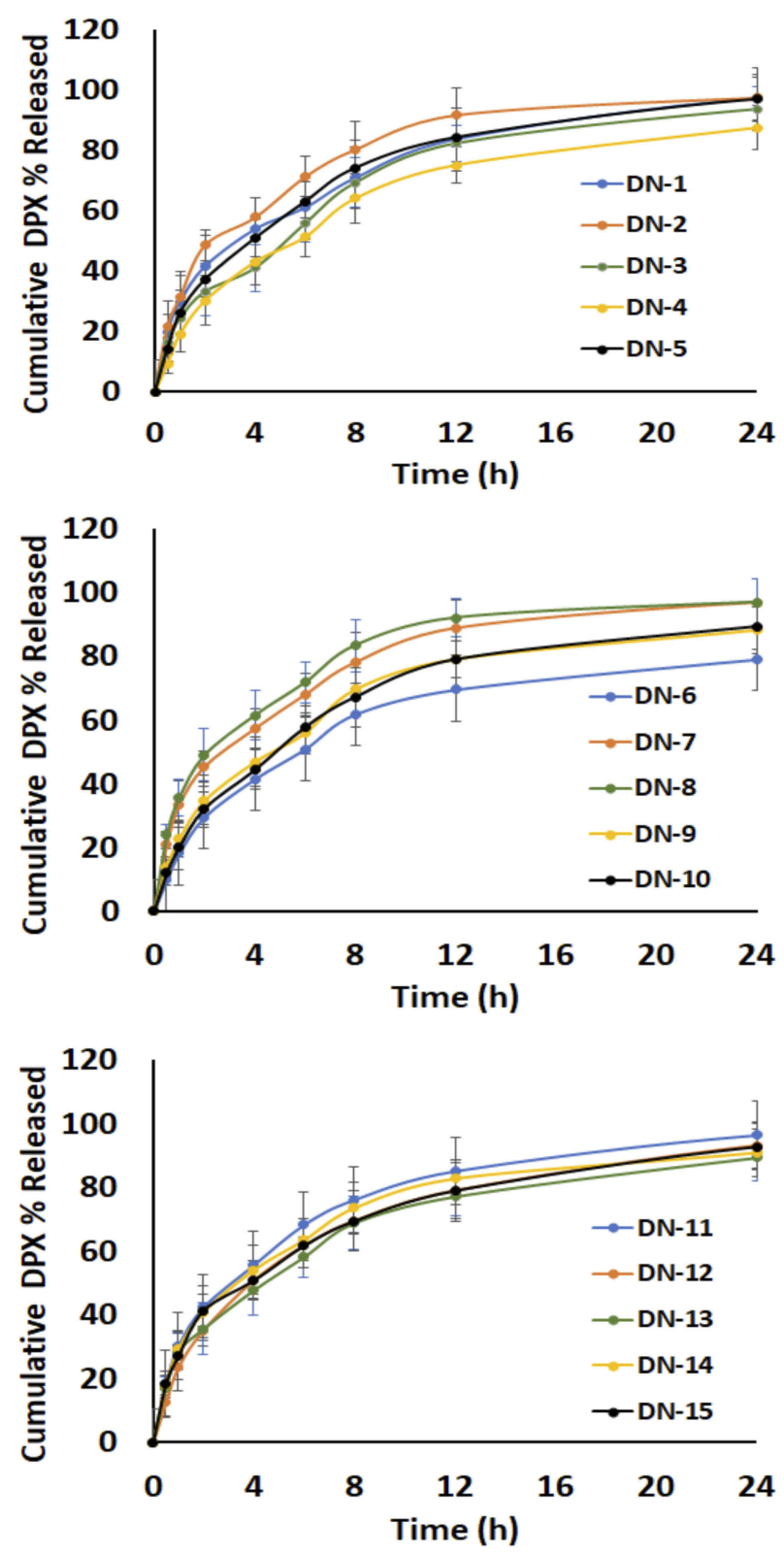

Figure 3 In vitro release profiles of DPX-loaded NPs formulations: (A) FI-F5; (B) F6-FI0; and (C) FII-FI5.

Abbreviations: DPX, dapoxetine; ALA, alpha lipoic acid.

with DN-6 showing the least release (79.05\%) (Table 2). Regression analysis with ANOVA detected that both $\mathrm{Y}_{3}$ and $\mathrm{Y}_{4}$ are governed by the percentage of ALA in Zein $\left(\mathrm{X}_{1}\right)$, which had a significant antagonistic effect on $\mathrm{Y}_{3}$, and $\mathrm{Y}_{4}$ with $p$-values of 0.0001 , and 0.0032 , respectively (Table 3 and Figure 1C, D and 2D-F). Also, the stirring rate $\left(\mathrm{X}_{3}\right)$ was found to have a significant antagonistic effect on the initial DPX release percentage after $1 \mathrm{~h}$ $\left(\mathrm{Y}_{3}\right)$ with a $p$-value of 0.0002 . Also, it was noticed that the quadratic term of $X_{1}$ had a significant antagonistic effect on $\mathrm{Y}_{3}$ with a $p$-value of 0.0013 . Finally, it was 
also noticed that the initial DPX release percentage after $1 \mathrm{~h}\left(\mathrm{Y}_{3}\right)$ was significantly affected by the interaction terms $\mathrm{X}_{1} \mathrm{X}_{2}$ and $\mathrm{X}_{1} \mathrm{X}_{3}$ with $p$-values of 0.0259 and 0.0026 , respectively. The equations (6 and 7 ) predicted the responses $\mathrm{Y}_{3}$ and $\mathrm{Y}_{4}$ :

$$
\begin{aligned}
\mathrm{Y}_{3}= & -84.2788+6.5815 \mathrm{X}_{1}-3.8925 \mathrm{X}_{2}+0.1007 \mathrm{X}_{3} \\
& -0.1358 \mathrm{X}_{1}^{2}+0.627 \mathrm{X}_{1} \mathrm{X}_{2}-0.00278 \mathrm{X}_{1} \mathrm{X}_{3} \\
& +2.11 \mathrm{X}_{2}^{2}-0.0125 \mathrm{X}_{2} \mathrm{X}_{3}-0.000008 \mathrm{X}_{3}^{2}
\end{aligned}
$$

$$
\begin{aligned}
\mathrm{Y}_{4}= & 148.252+2.4358 \mathrm{X}_{1}-21.4725 \mathrm{X}_{2}-0.12905 \mathrm{X}_{3} \\
& -0.0975 \mathrm{X}_{1}^{2}+0.948 \mathrm{X}_{1} \mathrm{X}_{2}-0.0005 \mathrm{X}_{1} \mathrm{X}_{3} \\
& +7.25 \mathrm{X}_{2}^{2}-0.009 \mathrm{X}_{2} \mathrm{X}_{3}+0.00008 \mathrm{X}_{3}^{2}
\end{aligned}
$$

Data obtained from the release profiles indicate (Table 2 and Figure 3) that, the percentage of ALA increased in the polymeric matrix $\left(\mathrm{X}_{1}\right)$ significantly impacted both the initial and cumulative DPX release. An increase in $X_{1}$ from 15 to $25 \%$, at the same level of $X_{2}$ and $X_{3}$, led to a decrease in $\mathrm{Y}_{3}$ from 29.68 to $22,7 \%$ for DN-1 and DN-9, respectively. Similar observation found in DN-2 and DN-6 where $\mathrm{Y}_{3}$ decreased from 31.34 to $18.09 \%$, and 23.54 to $19.1 \%$ for DN-12 and DN-4, respectively. The same formulations revealed a similar trend regarding the cumulative DPX release $\left(\mathrm{Y}_{4}\right)$. This behavior can be explained by the release of surface bound DPX from Zein-loaded NPs during the initial rapid release phase. DPX diffusion from NPs core is responsible for the controlled release phase. In addition, the hydrophobic nature of Zein and ALA NPs can sustain the encapsulated DPX release.

Moreover, it was found that there is a direct relationship between the stirring rate $\left(\mathrm{X}_{3}\right)$ and the initial DPX release $\left(\mathrm{Y}_{3}\right)$. The initial DPX release decreased from 20.1 to $19.1 \%$ in $\mathrm{DN}-10$ and $\mathrm{DN}-4$, respectively when the stirring rate was decreased from 1200 to $800 \mathrm{rpm}$ at an equal level of $\mathrm{X}_{1}$ and $\mathrm{X}_{2}$. Also, $\mathrm{Y}_{3}$ decreased from 35.67 to $23.54 \%$ in $\mathrm{DN}-8$ and $\mathrm{DN}-12$, respectively by decreasing $\mathrm{X}_{3}$ from 1200 to $800 \mathrm{rpm}$ at the same level of $X_{1}$ and $X_{2}$. We observed a similar decrease of $\mathrm{Y}_{3}$ from 33.45 to $24.34 \%$ for $\mathrm{DN}-7$ and $\mathrm{DN}-3$, respectively due to the decrease in $X_{3}$ from 1200 to $800 \mathrm{rpm}$ at the same level of $X_{1}$ and $X_{2}$. This finding may be due to the size reduction of the NPs by increasing the stirring rate, which permits greater surface area in contact with the dissolution media that promotes penetration of NPs, consequently improving the drug dissolution and increasing the initial drug release.

\section{Validation of optimized DPX-loaded NPs}

Box-Behnken experimental design deduced the optimum DPX-loaded NPs formulation that was prepared and evaluated. The obtained results indicated that combination of independent factors for the optimized DPX-loaded NPs formulation showed the desired particle size of $159.24 \mathrm{~nm}$ with polydispersity index value of 0.140 (Figure 4A) and zeta potential of $19.14 \mathrm{mV}$ (Figure 4B). In addition, the optimized formulation releases $25.32 \%$ of its DPX content in the first hour and 95.89\% after $24 \mathrm{hrs}$. The results of the observed and the predicted values are shown in Table 4 that demonstrated no considerable residuals, and the predicted error percentage of the responses were less than $6 \%{ }^{42}$

\section{Morphological examination of the optimized DPX-loaded NPs}

We undertook a morphological examination of the optimized DPX-loaded NPs to confirm the spherical morphology of the optimized NPs. SEM photomicrographs at different magnification (Figure $4 \mathrm{C}$ and $\mathrm{D}$ ) revealed the spherical shape with the smooth surface of the optimized DPX-loaded NPs. The mechanical stress of ice crystals during the lyophilization process could be behind the aggregation of the NPs displayed in the images. ${ }^{43}$ TEM images (Figure 4E and F) confirmed the spherical structure with a dark core of the NPs. No aggregation was observed, and the size of the NPs was in good agreement with that obtained employing the dynamic light scattering technique. The results suggest uniformity of size distribution of the prepared NPs.

\section{Single-dose clinical pharmacokinetics investigation of the optimized DPX NPs formulation on healthy human volunteers}

To study the bioavailability of DPX-loaded NPs, human volunteers were given single oral administration of $30 \mathrm{mg}$ of DPX-loaded NPs. The results presented in Figure 5 and Table 5 show a significant difference $(p<0.05)$ of $t_{\max }$,

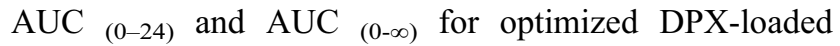
NPs when compared with the marketed DPX tablet. DPX-loaded NPs significantly prolonged $t_{\max }$ by 4-fold $(2.5 \pm 0.314 \mathrm{~h}$ vs. $0.583 \pm 0.144 \mathrm{~h}$, respectively), AUC by 2-fold, with a slight reduction of $t_{1 / 2}(5.283 \pm 1.077 \mathrm{~h}$ vs $8.452 \pm 2.813 \mathrm{~h}$ ). On the other hand, the data showed no significant difference $(p<0.05)$ in the $\mathrm{C}_{\max }$ values of the NPs formulation compared with the marketed DPX tablet. 
(A)

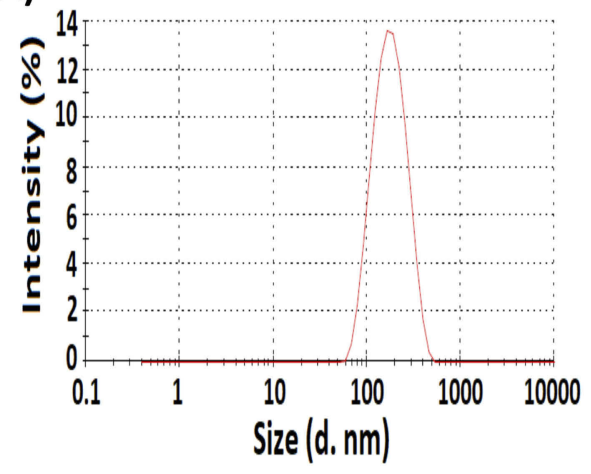

(C)

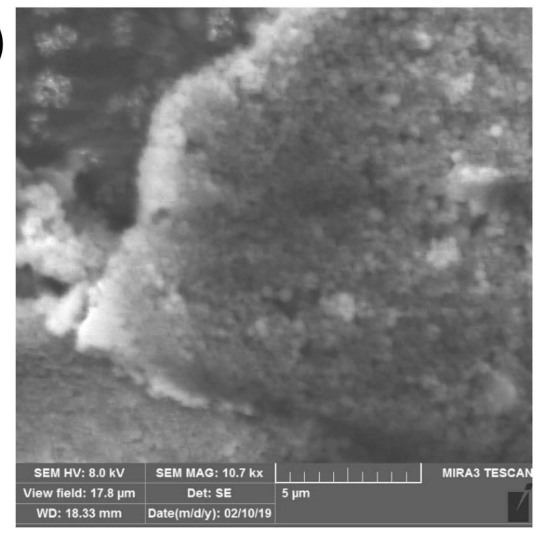

(E)

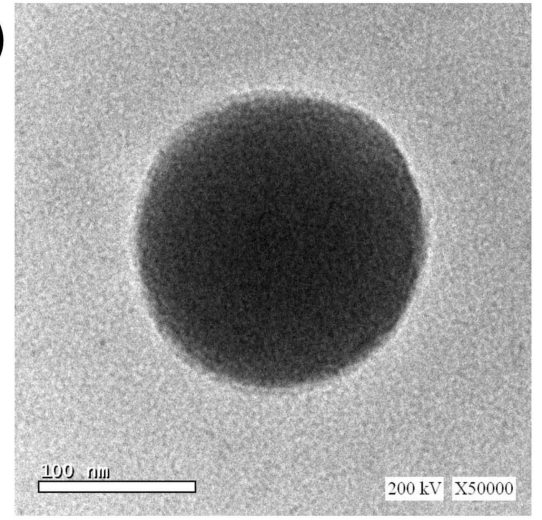

(B)

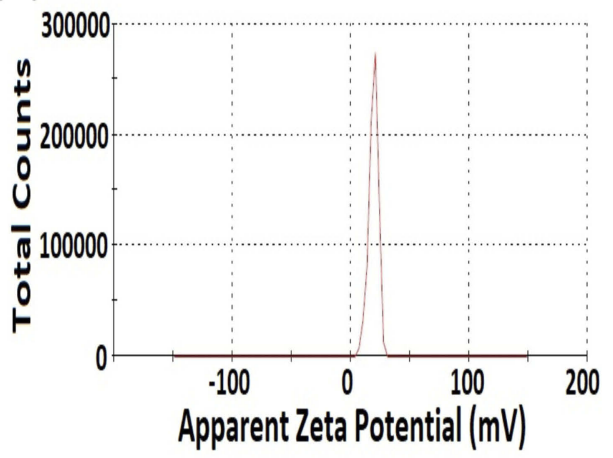

(D)

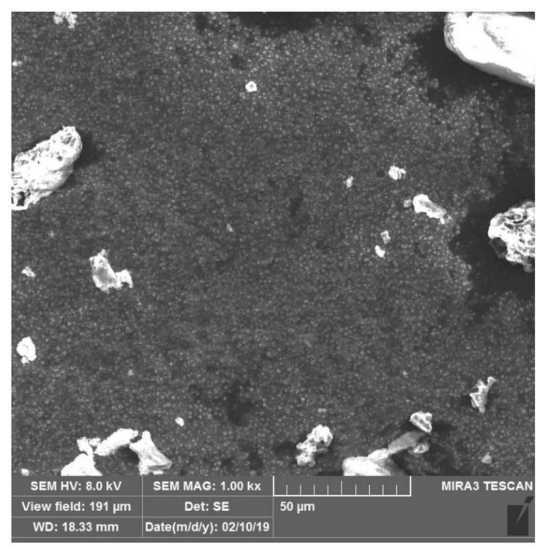

(F)

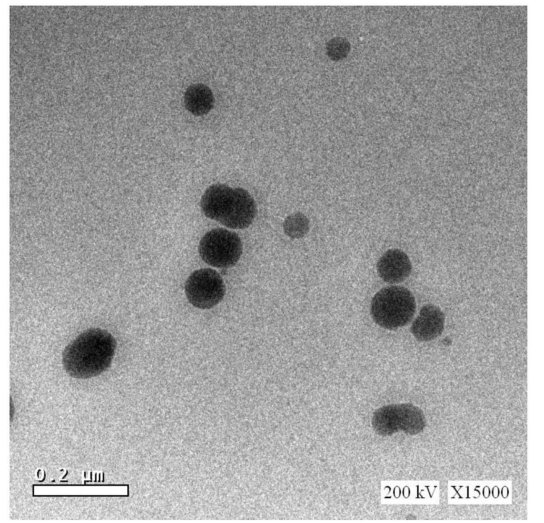

Figure 4 Particle size distribution (A), zeta potential (B) measured by particle size analyzer, SEM photomicrographs (C and D) and TEM images (E and F) of optimized DPX-loaded NPs.

Abbreviations: TEM, Transmission electron microscope; DPX, dapoxetine; ALA, alpha lipoic acid.

Most importantly, the optimized DPX-loaded NPs formulation showed 194\% improved relative bioavailability when compared to the marketed tablet. The reduction of DPX half-life $\left(\mathrm{t}_{1 / 2}\right)$ in the DPX-loaded NPs is most likely due to the improved permeability, absorption and distribution of DPX, from the NPs formulation to the second compartment tissue. This could be related to reduced particle size (to the nanoscale range) formulation that leads to enhanced DPX oral absorption with rapid elimination. The enhancement in the bioavailability is likely due to the prolongation in the MRT of the NPs to $7.637 \pm 1.373 \mathrm{~h}$ compared to $6.031 \pm 1.826 \mathrm{~h}$ for the marketed tablet. Prolongation in MRT was accompanied by prolongation in the $t_{\max }$ from $0.583 \pm 0.144 \mathrm{~h}$ of the tablet to $2.5 \pm 0.314 \mathrm{~h}$ of the NPs. Prolongation of the $t_{\max }$ and MRT of the DPX in the NPs could be due to the controlled release behavior of the encapsulated DPX in the NPs. Also, the presence of Zein and ALA in the formulation may be sterically 
Table 4 Optimal calculated variables and observed, predicted and residual values for responses $\left(Y_{1}-Y_{4}\right)$

\begin{tabular}{|l|l|l|l|l|l|}
\hline Factor & Optimum & Response & Predicted & Observed & Residual \\
\hline $\mathbf{X}_{\mathbf{1}}(\%)$ & 15 & $\mathbf{Y}_{\mathbf{1}}(\mathbf{n m})$ & 161.88 & 159.24 & 2.64 \\
\hline $\mathbf{X}_{\mathbf{2}}(\%)$ & 0.5 & $\mathbf{Y}_{\mathbf{2}}(\mathbf{m V})$ & 19.49 & 19.14 & 0.35 \\
\hline $\mathbf{X}_{\mathbf{3}}(\mathbf{r p m})$ & 800 & $\mathbf{Y}_{\mathbf{3}}(\%)$ & 24.22 & 25.32 & 1.10 \\
\hline & & $\mathbf{Y}_{\mathbf{4}}(\%)$ & 97.19 & 95.89 & 1.29 \\
\hline
\end{tabular}

Abbreviations: $X_{1}$, percentage of alpha lipoic acid in zein; $X_{2}$, polyvinyl alcohol \% concentration; $X_{3}$, stirring rate; $Y_{1}$, particle size $(n m) ; Y_{2}$, zeta potential $(m V) ; Y_{3}$, initial permeation after $\mathrm{Ih}(\%)$; $\mathrm{Y}_{4}$, cumulative permeation after $24 \mathrm{~h}(\%)$.

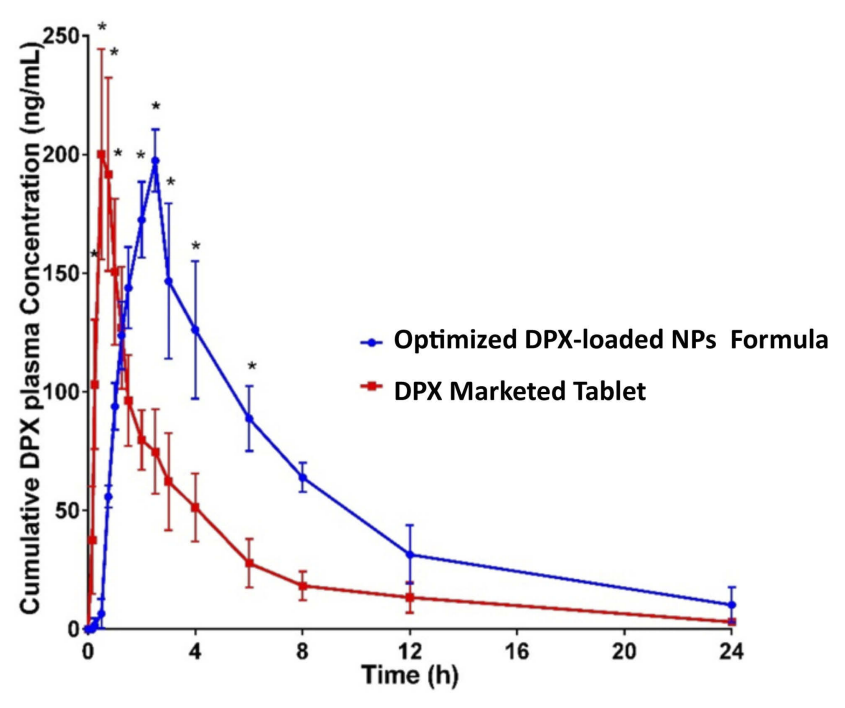

Figure 5 Plasma concentration-time profiles for the optimized DPX-zein-ALA nanospheres and marketed DPX tablets $(30 \mathrm{mg}$ ) administered orally as a single dose. Data represent the mean value \pm standard deviation $(n=6)$. *Significant at $P<0.05$ (two-way ANOVA, Sidak's multi-comparison test). hindering the uptake of NPs by the tissue through the reticuloendothelial system that decreases its rate of clearance from the body. ${ }^{29,44}$ In addition, the N-terminal region for Zein protein interacts with cell membranes and serve as a peptide carrier for drugs and thus enhances paracellular permeability. ${ }^{45}$ These features underpin the enhanced bioavailability of the developed DPX-loaded NPs formulation.

\section{Conclusion}

The introduction of DPX for the treatment of PE eliminates the reliance on other non-approved treatments, however, it is fraught with low bioavailability leading to a high therapeutic dose and adverse effect. We have successfully developed an optimized DPX-Zein-ALA formulation that has resulted in the improvement of oral bioavailability of DPX in human volunteers when compared to the marketed

Table 5 Single dose clinical pharmacokinetic parameters after oral administration of $30 \mathrm{mg}$ of optimized DPX-loaded NPs and DPX marketed tablets

\begin{tabular}{|c|c|c|}
\hline Pharmacokinetic Parameter & Optimized DPX-loaded NPs & DPX Marketed Tablets \\
\hline $\mathrm{C}_{\max }(\mathrm{ng} / \mathrm{mL})$ & $197.384 \pm 13.153$ & $200.12 I \pm 44.35 I$ \\
\hline$t_{\max }(h)$ & $2.5 \pm 0.314 *$ & $0.583 \pm 0.144$ \\
\hline $\mathrm{AUC}_{(0-24)}(\mathrm{ng} \cdot \mathrm{h} / \mathrm{mL})$ & $1290.375 \pm 262.169 *$ & $662.758 \pm 116.011$ \\
\hline $\operatorname{AUC}_{(24-\infty))}(\mathrm{ng} \cdot \mathrm{h} / \mathrm{mL})$ & $85.77 \pm 79.191$ & $46.419 \pm 31.879$ \\
\hline $\mathrm{AUC}_{(0-\infty)}(\mathrm{ng} \cdot \mathrm{h} / \mathrm{mL})$ & $1376.145 \pm 339.592 *$ & $709.178 \pm 146.307$ \\
\hline AUMC $_{(0-24)} \mathrm{ng} \cdot \mathrm{hr}^{2} / \mathrm{mL}$ & $8749.718 \pm 2815.176$ & $3324.778 \pm 1226.219$ \\
\hline $\mathrm{AUMC}_{\text {(24-end) }} \mathrm{ng} \cdot \mathrm{hr}^{2} / \mathrm{mL}$ & $2058.47 I \pm 1900.592$ & 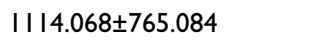 \\
\hline $\operatorname{AUMC}_{(0-\infty)} \mathrm{ng} \cdot \mathrm{hr}^{2} / \mathrm{mL}$ & $10,808.189 \pm 4708.753$ & $4438.846 \pm \mid 991.228$ \\
\hline $\mathrm{K}_{\mathrm{el}}\left(\mathrm{h}^{-1}\right)$ & $0.135 \pm 0.025$ & $0.089 \pm 0.032$ \\
\hline$t_{1 / 2}(h)$ & $5.283 \pm 1.077$ & $8.452 \pm 2.813$ \\
\hline MRT (h) & $7.637 \pm 1.373$ & $6.031 \pm 1.826$ \\
\hline Relative bioavailability (\%) & 194.04 & - \\
\hline
\end{tabular}

Notes: Data represent the mean value \pm standard deviation (SD) $(n=6)$, *Significant at $P<0.05$ unpaired $t$ test (two-tailed). 
DPX tablet. These results revealed the ability of the NPs formulation to improve the delivery and effect of DPX that could be applied successfully in the management of male PE.

\section{Acknowledgment}

This project was funded by the Deanship of Scientific Research (DSR) at King Abdulaziz University, Jeddah, under grant no. (RG-1-166-39). The authors, therefore, acknowledge with thanks DSR technical and financial support.

\section{Disclosure}

The authors report no conflicts of interest to declare in this work.

\section{References}

1. Althof SE, Abdo CHN, Dean J, et al. International Society for Sexual Medicine's Guidelines for the Diagnosis and Treatment of Premature Ejaculation. Vol. 7. Elsevier Masson SAS; Issy-les-Moulineaux, France 2010. doi:10.1111/j.1743-6109.2010.01975.x

2. Laumann EO, Nicolosi A, Glasser DB, et al. Sexual problems among women and men aged 40-80 y: prevalence and correlates identified in the Global Study of Sexual Attitudes and Behaviors. Int J Impot Res. 2004;17:39. doi:10.1038/sj.ijir.3901250

3. Nicolosi A, Laumann EO, Glasser DB, Moreira ED Jr, Paik A, Gingell C. Sexual behavior and sexual dysfunctions after age 40: the global study of sexual attitudes and behaviors. Urology. 2004;64 (5):991-997. doi:10.1016/j.urology.2004.06.055

4. Patel K, Hellstrom WJG. Central regulation of ejaculation and the therapeutic role of serotonergic agents in premature ejaculation. Curr Opin Investig Drugs. 2009;10(7):681-690. Available from: http://www. ncbi.nlm.nih.gov/pubmed/19579174. Accessed October 27, 2018.

5. Kendirci M, Salem E, Hellstrom WJ. Dapoxetine, a novel selective serotonin transport inhibitor for the treatment of premature ejaculation. Ther Clin Risk Manag. 2007;3(2):277-289. Available from: http://www.ncbi.nlm.nih.gov/pubmed/18360636. Accessed October 27, 2018.

6. McCarty E, Dinsmore W. Dapoxetine: an evidence-based review of its effectiveness in treatment of premature ejaculation. Core Evid. 2012;7:1-14. doi:10.2147/CE.S13841

7. McMahon CG. Dapoxetine: a new option in the medical management of premature ejaculation. Ther Adv Urol. 2012;4(5):233-251. doi:10. $1177 / 1756287212453866$

8. European Medicines Agency. Priligy; 2012. Available from: https:// www.ema.europa.eu/en/medicines/human/referrals/priligy. Accessed October 27, 2018.

9. ANDERSSON K-E, MULHALL JP, WYLLIE MG. Pharmacokinetic and pharmacodynamic features of dapoxetine, a novel drug for "ondemand" treatment of premature ejaculation. BJU Int. 2006;97 (2):311-315. doi:10.1111/j.1464-410X.2006.05911.x

10. Modi NB, Dresser MJ, Simon M, Lin D, Desai D, Gupta S. Singleand multiple-dose pharmacokinetics of dapoxetine hydrochloride, a novel agent for the treatment of premature ejaculation. $J$ Clin Pharmacol. 2006;46(3):301-309. doi:10.1177/0091270005284850

11. Thyssen A, Sharma O, Tianmei S, et al. Pharmacokinetics of dapoxetine hydrochloride in healthy Chinese, Japanese, and Caucasian men. J Clin Pharmacol. 2010;50(12):1450-1460. doi:10.1177/ 0091270009359183
12. McMahon CG. Dapoxetine for premature ejaculation. Expert Opin Pharmacother. 2010;11(10):1741-1752. doi:10.1517/ 14656566.2010.493174

13. Algandaby MM, Al-Sawahli MM, Ahmed OAA, et al. Curcumin-zein nanospheres improve liver targeting and antifibrotic activity of curcumin in carbon tetrachloride-induced mice liver fibrosis. $J$ Biomed Nanotechnol. 2016;12(9):1746-1757. doi:10.1166/jbn.2016.2270

14. Hashem FM, Al-Sawahli MM, Nasr M, Ahmed OAA. Optimized zein nanospheres for improved oral bioavailability of atorvastatin. Int J Nanomedicine. 2015;10. doi:10.2147/IJN.S83906.

15. Padua GW, Wang Q Controlled self-organization of zein nanostructures for encapsulation of food ingredients. In: ACS Symposium Series. Vol 1007.; 2009:143-156. doi:10.1021/bk-2009-1007.ch009

16. Ahmed OAA, Zidan AS, Khayat M. Mechanistic analysis of zein nanoparticles/PLGA triblock in situ forming implants for glimepiride. Int J Nanomedicine. 2016;11:543-555. doi:10.2147/IJN.S99731

17. Corradini E, Curti PS, Meniqueti AB, Martins AF, Rubira AF, Muniz EC. Recent advances in food-packing, pharmaceutical and biomedical applications of zein and zein-based materials. Int $J$ Mol Sci. 2014;15(12):22438-22470. doi:10.3390/ijms151222438

18. Bouman J, Belton P, Venema P, Van Der Linden E, De Vries R, Qi S. Controlled release from zein matrices: interplay of drug hydrophobicity and pH. Pharm Res. 2016;33(3):673-685. doi:10.1007/s11095015-1818-8

19. Alan C, Kocoglu H, Resit Ersay A, Anil Kurt H, Ertung Y, Alan H. [Biochemical changes in cavernosal tissue caused by single sided cavernosal nerve resection and the effects of alpha lipoic acid on these changes]. Actas Urol Esp. 2010;34(10):874-881. 13184376 [pii].

20. Caruso S, Iraci Sareri M, Casella E, Ventura B, Fava V, Cianci A. Chronic pelvic pain, quality of life and sexual health of women treated with palmitoylethanolamide and $\alpha$-lipoic acid. Minerva Ginecol. 2015;67(5):413-419. Available from: http://europepmc.org/ abstract/med/26491823. Accessed March 15, 2018.

21. Hamano Y. Effects of $\alpha$-lipoic acid supplementation on sexual difference of growth performance, heat exposure-induced metabolic response and lipid peroxidation of raw meat in broiler chickens. $\mathrm{Br}$ Poult Sci. 2014;55(3):343-350. doi:10.1080/00071668.2014.903559

22. Keegan A, Cotter MA, Cameron NE. Effects of diabetes and treatment with the antioxidant $\alpha$-lipoic acid on endothelial and neurogenic responses of corpus cavernosum in rats. Diabetologia. 1999;42 (3):343-350. doi:10.1007/s001250051161

23. Mitkov MD, Aleksandrova IY, Orbetzova MM. Effect of transdermal testosterone or alpha-lipoic acid on erectile dysfunction and quality of life in patients with type 2 diabetes mellitus. Folia Med (Plovdiv). 2013;55(1):55-63. Available from: https://www.degruyter.com/view/ $\mathrm{j}$ /folmed.2013.55.issue-1/folmed-2013-0006/folmed-2013-0006.xml. Accessed March 15, 2018.

24. Ahmed OAA. Development and single dose clinical pharmacokinetics investigation of novel zein assisted- alpha lipoic acid nanoencapsulation of vardenafil. Sci Rep. 2018;8(1):15802. doi:10.1038/ s41598-018-34235-8

25. Ahmed OAA, El-Say KM, Aljaeid BM, Badr-Eldin SM, Ahmed TA. Optimized vinpocetine-loaded vitamin E D- $\alpha$-tocopherol polyethylene glycol 1000 succinate-alpha lipoic acid micelles as a potential transdermal drug delivery system: in vitro and ex vivo studies. Int $J$ Nanomedicine. 2018;14:33-43. doi:10.2147/IJN.S187470

26. Ahmed OAA, Afouna MI, El-Say KM, Abdel-Naim AB, Khedr A, Banjar ZM. Optimization of self-nanoemulsifying systems for the enhancement of in vivo hypoglycemic efficacy of glimepiride transdermal patches. Expert Opin Drug Deliv. 2014;11(7). doi:10.1517/ 17425247.2014.906402

27. Doijad R, Manvi F, Godhwani D, Joseph R, Deshmukh N. Formulation and targeting efficiency of cisplatin engineered solid lipid nanoparticles. Indian J Pharm Sci. 2008;70(2):203. doi:10.41 03/0250-474X.41456 
28. Kim S-H, Lee SH, Lee HJ. Rapid and sensitive carvedilol assay in human plasma using a high-performance liquid chromatography with mass/mass spectrometer detection employed for a bioequivalence study. Am J Anal Chem. 2010;01(03):135-143. doi:10.4236/ ajac. 2010.13017

29. Aljaeid BM, El-Say KM, Hosny KM. Chitosan-TPP nanoparticles stabilized by poloxamer for controlling the release and enhancing the bioavailability of doxazosin mesylate: in vitro, and in vivo evaluation. Drug Dev Ind Pharm. 2019;45(7):1130-1139. doi:10.1080/ 03639045.2019.1597105

30. He C, Yin L, Tang C, Yin C. Size-dependent absorption mechanism of polymeric nanoparticles for oral delivery of protein drugs. Biomaterials. 2012;33(33):8569-8578. doi:10.1016/j.biomaterials.20 12.07 .063

31. El-Say KM, El-Sawy HS. Polymeric nanoparticles: promising platform for drug delivery. Int $J$ Pharm. 2017;528(1-2):675-691. doi:10.1016/j.ijpharm.2017.06.052

32. Weerakody R, Fagan P, Kosaraju SL. Chitosan microspheres for encapsulation of $\alpha$-lipoic acid. Int J Pharm. 2008;357(1-2):213218. doi:10.1016/j.ijpharm.2008.02.019

33. Bugs MR, Forato LA, Bortoleto-Bugs RK, et al. Spectroscopic characterization and structural modeling of prolamin from maize and pearl millet. Eur Biophys J. 2004;33(4):335-343. doi:10.1007/ s00249-003-0354-3

34. Muthuselvi L, Dhathathreyan A. Simple coacervates of zein to encapsulate Gitoxin. Colloids Surf B Biointerfaces. 2006;51(1):39-43. doi:10.1016/j.colsurfb.2006.05.012

35. Matsushima N, Danno GI, Takezawa H, Izumi Y. Three-dimensional structure of maize $\alpha$-zein proteins studied by small-angle X-ray scattering. Biochim Biophys Acta - Protein Struct Mol Enzymol. 1997;1339(1):14-22. doi:10.1016/S0167-4838(96)00212-9

36. El-Say KM. Maximizing the encapsulation efficiency and the bioavailability of controlled-release cetirizine microspheres using Draper - lin small composite design. Drug Des Devel Ther. 2016;10:825839. doi:10.2147/DDDT.S101900
37. Kim BK, Hwang SJ, Park JB, Park HJ. Preparation and characterization of drug-loaded polymethacrylate microspheres by an emulsion solvent evaporation method. J Microencapsul. 2002;19(6):811-822. doi:10.1080/0265204021000022770

38. Haznedar S, Dortunc B. Preparation and in vitro evaluation of Eudragit microspheres containing acetazolamide. Int $J$ Pharm. 2004;269(1):131-140.

39. $\mathrm{Hu} \mathrm{K}$, McClements DJ. Fabrication of surfactant-stabilized zein nanoparticles: A pH modulated antisolvent precipitation method. Food Res Int. 2014;64:329-335. doi:10.1016/j.foodres.2014.07.004

40. Nishiura H, Sugimoto K, Akiyama K, et al. A novel nano-capsule of $\alpha$-lipoic acid as a template of core-shell structure constructed by selfassembly. J Nanomed Nanotechnol. 2013;04(01):1-7. doi:10.4172/ 2157-7439.1000155

41. Wiśniewska M, Ostolska I, Szewczuk-Karpisz K, et al. Investigation of the polyvinyl alcohol stabilization mechanism and adsorption properties on the surface of ternary mixed nanooxide AST 50 (A12O3-SiO2-TiO2). J Nanopart Res. 2015;17(1):12. doi:10.1007/ s11051-014-2831-2

42. Mujtaba A, Ali M, Kohli K. Statistical optimization and characterization of $\mathrm{pH}$-independent extended-release drug delivery of cefpodoxime proxetil using Box-behnken design. Chem Eng Res Des. 2014;92(1):156-165. doi:10.1016/j.cherd.2013.05.032

43. Abdelwahed W, Degobert G, Stainmesse S, Fessi H. Freeze-drying of nanoparticles: formulation, process and storage considerations. $A d v$ Drug Deliv Rev. 2006;58(15):1688-1713. doi:10.1016/j.addr.2006. 09.017

44. Chen DB, Yang TZ, Lu WL, Zhang Q. In vitro and in vivo study of two types of long-circulating solid lipid nanoparticles containing paclitaxel. Chem Pharm Bull (Tokyo). 2001;49(11):1444-1447. doi:10.1248/cpb.49.1444

45. Fernández-Carneado J, Kogan MJ, Castel S, Giralt E. Potential peptide carriers: amphipathic proline-rich peptides derived from the Nterminal domain of $\gamma$-zein. Angew Chemie - Int Ed. 2004;43 (14):1811-1814. doi:10.1002/anie.200352540
International Journal of Nanomedicine

\section{Publish your work in this journal}

The International Journal of Nanomedicine is an international, peerreviewed journal focusing on the application of nanotechnology in diagnostics, therapeutics, and drug delivery systems throughout the biomedical field. This journal is indexed on PubMed Central, MedLine, CAS, SciSearch ${ }^{\circledR}$, Current Contents ${ }^{\mathbb{R}} /$ Clinical Medicine,
Journal Citation Reports/Science Edition, EMBase, Scopus and the Elsevier Bibliographic databases. The manuscript management system is completely online and includes a very quick and fair peer-review system, which is all easy to use. Visit http://www.dovepress.com/ testimonials.php to read real quotes from published authors. 